\title{
Do Not Accept the Status Quo!
}

\author{
Glen Brown
}

A s you provide pharmaceutical care to your patients, you intervene to alter the drug therapy of individual patients to give them the greatest opportunity of achieving the desired therapeutic goal. This represents a great service to your patients, and thousands of Canadians across the country benefit from pharmacists' involvement in their care. However, many of the problems requiring intervention from pharmacists occur over and over again. For example, you have probably intervened many times to have the dose of a medication altered because of impaired or improved drug clearance, such as occurs with changes in renal function. Similarly, recent interest in medication reconciliation reflects a recognition that interventions to address inappropriate drug therapy have been frequently required at points of transfer in care. The challenge to all care providers, including pharmacists, is to recognize situations in which drug therapy is repeatedly suboptimal and to initiate processes so that future patients will not have the same experience. With this in mind, are you recognizing the contributory factors to suboptimal care, and are you doing something about these problems?

In this issue of the CJHP, Louie and others ${ }^{1}$ describe a specific practice environment in Canadian hospitals where, they suggest, pharmacists and other care providers are not adequately organized to systematically document medication errors, evaluate the causes of the errors, and prevent subsequent problems with drug therapy. These investigators selected the intensive care unit setting for examination because of the critical nature of patients' conditions, the major contribution of drug therapy to patients' outcomes, and the potential for deleterious consequences with drug misadventures. Yet their findings could be extrapolated to many other practice environments where pharmacists are significant contributors to care. Louie and others were looking for structured methods of reporting, evaluating, and responding to medication errors, but I am sure that their examination could be expanded to investigate all types of drug-related problems. I am not suggesting that every intervention by a pharmacist is in response to a medication error, but I think the authors' inquiry into why pharmacists' interventions are not used as a method for tracking suboptimal care has validity. How often have you stopped to ask yourself, "Why do I need to perform this intervention?" rather than just going ahead with the intervention? I suspect that only infrequently do you investigate the causes of a recurring drug-related problem and that much more frequently you just intervene. By doing so, are we pharmacists not simply allowing the same thing to happen again in the future? Are we not too easily accepting the status quo as the way it has to be?

The challenge to us all, whatever our practice environment, is to look beyond the individual patient and his or her problems and to seek out the potentially correctable causes or patterns that may have contributed to the problem. A key component in this process is a system for recording the occurrence of drug-related problems and any contributing factors. Louie and others used medication error as one example of a drug-related problem worthy of monitoring and investigation, but others, such as drug selection, duration of therapy, or drug dosage, could also be selected. Many Canadian hospital pharmacies maintain a clinical workload measurement system where types of interventions are recorded. It would be a small step to include data on the drug or disease process associated with the intervention. ${ }^{2}$ Louie and others suggest that many Canadian pharmacists practise in an environment where voluntary paper reporting is the standard. They appropriately note that voluntary reporting is inadequate for documenting the frequency of and contributors to medication errors. Others have found that online reporting is more efficient and more comprehensive in identifying problems with drug therapy. ${ }^{3}$ Adequate documentation will allow identification of patterns of drug use or drug-disease combinations that are frequently associated with drug-related problems requiring intervention. Further investigation into the contributing factors should help in identifying steps that could be altered to minimize recurrence of the drug-related problem.

Pharmacists should be active in developing processes to systematically explore the source of drug-related problems. ${ }^{3,4}$ Do not accept the status quo, but rather, be leaders of change! Your future patients will benefit. The Journal welcomes reports on how you have established processes for systematically recording and evaluating any or all aspects of problems with drug therapy so that others can learn from your successes. 
References

1. Louie K, Wilmer A, Wong H, Grubisic M, Ayas N, Dodek P. Medication error reporting systems: a survey of Canadian intensive care units. Can J Hosp Pharm 2010;63(1):20-24.

2. Raybardhan S, Balen RM, Partovi N, Loewen P, Liu G, Jewesson PJ. Documenting drug-related problems with personal digital assistants in a multisite health system. Am J Health Syst Pharm 2005;62(17):1782-1787.

3. Savage SW, Schneider PJ, Pedersen CA. Utility of an online medicationerror-reporting system. Am J Health Syst Pharm 2005;62(21):2265-2270.

4. Costello JL, Torowicz DL, Yeh TS. Effects of a pharmacist-led pediatrics medication safety team on medication-error reporting. Am J Health Syst Pharm 2007;64(13):1422-1426.
Glen Brown, BSc(Pharm), PharmD, FCSHP, BCPS, is a Clinical Pharmacy Specialist, Pharmacy Department, St Paul's Hospital, Vancouver, British Columbia. He is also an Associate Editor with CJHP.

\section{Address correspondence to:}

Dr Glen Brown

Pharmacy Department

St Paul's Hospital

1081 Burrard Street

Vancouver BC V6H $1 \mathrm{G} 7$

e-mail: gbrown@providencehealth.bc.ca

\section{ON THE FRONT COVER}

\section{Sheppard Road, Mill Bay Vancouver Island, British Columbia}

This photograph was taken in late December 2008 on Sheppard Road in Mill Bay, British Columbia. Mill Bay is located on Vancouver Island, about 45 minutes north of Victoria. The

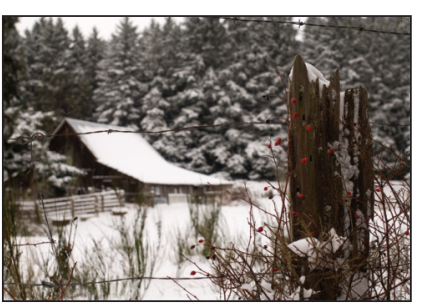

photographer was Ryan Barry, brother of pharmacist and CSHP member Arden Barry. The image, obtained with a Nikon D70 digital camera, depicts a barn located on the Barrys' grandparents' property on an unusually snowy December day.

The CJHP would be pleased to consider photographs featuring Canadian scenery taken by CSHP members for use on the front cover of the journal. If you would like to submit a photograph, please send an electronic copy (minimum resolution $300 \mathrm{dpi}$ ) to Sonya Long at slong@cshp.ca. 